\title{
There are Two Different Language Systems in the Brain
}

\author{
Alfredo Ardila \\ Department of Communication Sciences and Disorders Florida International University, Miami, USA \\ E-mail: ardilaa@fiu.edu
}

Received February 12, 2011; revised March 26, 2011; accepted March 28, 2011

\begin{abstract}
In this paper it is emphasized that human language has two rather different dimensions corresponding to two different language systems: lexical/semantic and grammatical. These two language systems are supported by different brain structures (temporal and frontal), and based in different learning strategies (declarative and procedural). In cases of brain pathology, each one can be independently impaired (Wernicke aphasia and Broca aphasia). While the lexical/semantic language system may have appeared during human evolution long before the contemporary man, the grammatical language system probably represents a relatively recent acquisition. Language grammar may be the departing ability for the development of the metacognitive executive functions and is probably based in the ability to internally represent actions.
\end{abstract}

Keywords: Language Evolution, Grammar, Aphasia, Executive Functions

\section{Introduction}

It is usually assumed that throughout human history (and also during child language development) there is a continuous and progressive complexization of language [1,2]. Thus, it is supposed that the child acquires the first words around the age of 12 months [3]; at this age the ability to repeat what he/she hears as a result of the maturation of the arcuate fasciculus also develops [4]; and later when the vocabulary reaches a large enough number of words, he/she begins to combine them, initially two words, further three and more words, some of them with a purely connecting (grammatical) function [2]. Consequently, it is generally assumed that there is a steady progression in language evolution and language development.

In this paper it is emphasized that human language indeed has two rather different dimensions: lexical/ semantic and grammatical, correlated with two different evolutionary patterns. The lexical/semantic system (i.e., representing external elements with sounds) has its roots in the animal communication systems, and most likely has existed since the early hominids, and even before [5]. The emergence of grammar (set of structural rules governing the composition of sentences -syntax- and words -morphology-) in human evolution is not just a quantitative but rather qualitative change (e.g., [6]), probably associated with the emergence of the so-called metacognitive executive functions (problem solving, planning, concept formation, strategy development and implementation, controlling attention, working memory, and the like) [7]. The emergence of grammar represents indeed the most crucial leap in human language evolution.

These two language systems (lexical/semantic and grammatical) are correlated with the activity of two distinct brain areas of the left hemisphere (temporal and frontal) (e.g., [8,9]); they are mediated by different learning processes (explicit and implicit memory) [10-14] and they appear during ontogeny and phylogeny at two different moments [1,2]. Clinical observations clearly demonstrate that there are two major aphasia syndromes (Wernicke-type and Broca-type aphasia) (for a review, see: [15]) due to damage in rather different brain areas (temporal and frontal) and associated with the impairment of each one of these language dimensions (lexical/ semantic and grammatical) (Figure 1).

This distinction between a lexical/semantic and a grammatical system is obviously well known in linguistics. For instance, Jakobson [16] referred to two different language axes (paradigmatic - lexical/semantic; and syntagmatic - grammatical); and Chomsky [17] clearly illustrated that the lexical/semantic system is independent from the grammatical system. Nonetheless, in cognitive neurosciences such a distinction is frequently obscured by the assumption that there are several (seven and even more) forms of language disturbances (aphasias) (e.g., [18-23]) associated with focal brain damage. There 


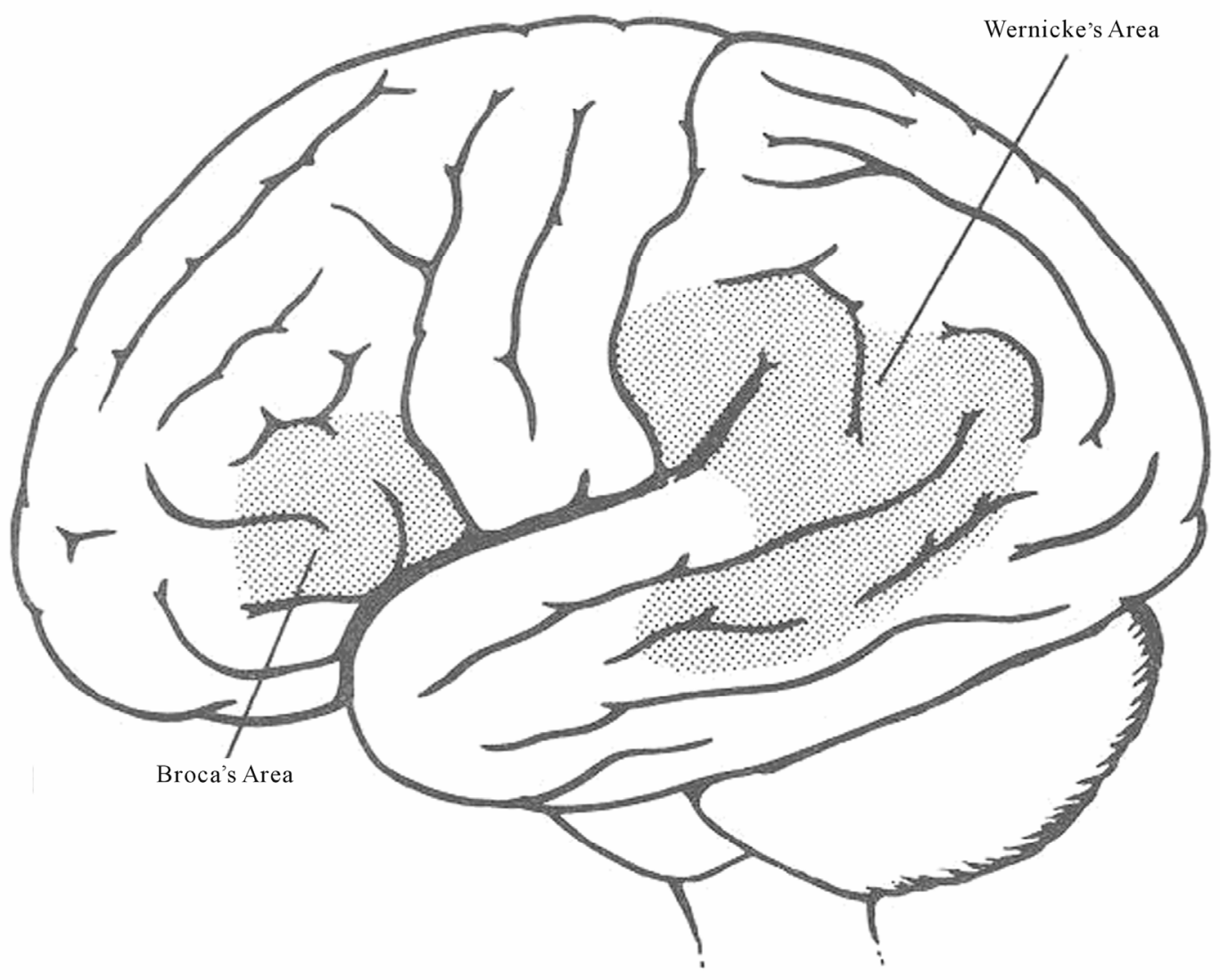

Figure 1. Traditionally it has been accepted that there are two major areas involved in language: frontal Broca's area and temporal Wernicke's area.

is the implicit assumption that language includes a diversity of functions (phoneme discrimination, lexical memory, grammar, repetition, language initiation ability, etc.), each one associated with the activity of a specific brain area. The different aphasia subtypes (Broca aphasia, conduction aphasia, Wernicke aphasia, aphasia of the supplementary motor area, transcortical sensory aphasia, etc.) are interpreted as conceptually equivalent, and in each one a specific language function or ability is supposed to be disturbed. Hence, it is concluded that there are seven (and even more) language functions.

\section{Experiment}

\subsection{Initial Communication Systems}

The origin of human language remains controversial and different explanatory proposals have been presented (e.g., $[1,24,25]$. Ardila [26] suggested that human language evolved through three different stages:

1) Initial communication systems using sounds and other types of information - such as gestures, etc., simi- lar to the communication systems observed in other animals, including nonhuman primates [27].

2) Primitive language systems using combined sounds (words) but without a grammar (language as a lexical/ semantic system). This type of language probably existed in other hominids [5] and could be linked to the holophrasic period in language development, observed in children around 1 to 1.5 years of age [2,3].

3) By the end of the second year, children begin to combine words into simple sentences. Initially, sentences have a telegraphic style (telegraphic speech) (around 24 30 months of age), including two-word utterances in which connecting elements are omitted (e.g., “dog big”) [2]; later, words with a grammatical function are found. Probably this type of language is historically recent and can be observed only in the Homo sapiens likely linked to some specific genetic mutations $[6,28,29]$. No question, the emergence of a grammatical language represents a crucial leap in human evolution.

It simply means that likely language initially emerges as a system of words with a particular content (meaning) (lexical/semantic system), and only later as a system of 
relations (grammatical system). Bickerton [30] developed the idea that a protolanguage must have preceded the full-fledged syntax of today's discourse. Echoes of this protolanguage can be seen, he argued, (a) in pidgin languages, (b) in the first words of infants, (c) in the symbols used by trained chimpanzees, and (d) in the syntax free utterances of children who do not learn to speak at the normal age. Bickerton [30] considers that such a proto-language existed already in the earliest Homo (about 2.3 to 2.4 million years), and was developed due to the pressure of the behavioral adaptations faced by Homo habilis (2.3 to 1.4 million years ago).

It is easy to assume that at the beginning of the human language, communication systems were similar to the communication systems found in nonhuman primates. It is known that chimpanzees and other nonhuman primates in their natural environment can use some communication strategies [27]. Chimpanzees employ a variety of gestures and facial expressions to communicate and keep in touch with each other. They possess a simple repertoire of noises and postures (body language) that can be used in different contexts with specific communication purposes. Observations have been collected in different environments, including natural environments and captive groups in human controlled environments [31]. Chimpanzees make use of simple gestures, make facial expressions and produce a limited amount of vocalizetions. Unlike humans, chimps only produce about 12 different vocalizations. In captive conditions and under human training, chimpanzees can learn some artificial languages and close to about 200 "words" [31,32].

Different attempts have been made to teach nonhuman primates to use more complex communication systems. Initially, Hayes and Hayes [33] trained the chimp Vicki. She became able to produce only four different words in six years! (“mom," "pa," "cup,” and "up”). Other chimps and gorillas have also participated in communication training programs: Nim and Koko used signs; Sara used plastic chips; Lana, Sherman, and Austion manipulated combinations of buttons to communicate [34-36].

Regardless of the relatively large amount of meaningful elements that chimpanzees can learn, they fail in developing sequencing of elements (syntax). Kanzi learned to use around 200 symbols on a portable electronic symbol board but learning grammar was not evident. It has been pointed out that while chimpanzees can learn to order their symbols to get what they want, it is not clear that they have mastered syntax $[37,38]$. The reason is that when they initiate communication, they often abandon the order they have learned and word order becomes random.

The question becomes: how this type of simple communication system found in nonhuman primates in natu- ral conditions (i.e., to use some few vocalizations, gestures and facial expressions) further developed into contemporary human language? Certain mechanisms potentially could be used to create meaningful sequences of sounds (i.e., words); for example, new words can be created departing from onomatopoeias, emotional expressions, interjections, gestures, etc. Indeed, a diversity of mechanisms has been proposed to account for how human words emerged [39]. This is an ability that is not found in nonhuman primates. Using these strategies certainly requires a brain notoriously more advanced than the chimpanzee's brain. Interestingly, it has been found that the arcuate fasciculus is much smaller or absent in nonhuman primates (chimpanzees and macaques) compared with humans [40], potentially limiting the language repetition ability and the possibility to transmit language from parents to children.

\subsection{The Lexical/Semantic System}

Paleoneurology (study and analysis of fossil endocasts) can significantly contribute to the understanding of the origins of the language. How did the brain areas participating in human lexical/semantic knowledge (i.e., left temporal lobe) evolve?

It is known that in monkeys, the temporal lobes are involved in recognizing the sounds and calls of the own species [41-44], and evidently the temporal lobe was a crucial area in developing a complex lexical/semantic system. Human sounds and calls are obviously at the origin of language words. Gannon et al. [45] observed that the anatomic pattern and left hemisphere size predominance of the planum temporale, a language area of the human brain, are also present in chimpanzees. They found that the left planum temporale was significantly larger in $94 \%$ of chimpanzee brains examined. Hence, the crucial lexical/semantic difference between humans and chimpanzees cannot be related to the planum temporale. By the same token, it has been observed that anatomical temporal-lobe asymmetries favoring the left hemisphere are found in several Old and New World monkey species [46]. Hopkins and Nir [47] examined whether chimpanzees show asymmetries in the planum temporale for grey matter volume and surface area in a sample of 103 chimpanzees from magnetic resonance images. The results indicated that, overall, the chimpanzees showed population-level leftward asymmetries for both surface area and grey matter volumes. Furthermore, chimpanzees that prefer to gesture with their right-hand had significantly greater leftward grey matter asymmtries compared to ambiguously- and left-handed apes. Development of a human lexical/semantic communiction system in consequence cannot be related to the temporal 
lobe asymmetry, because this asymmetry is observed long before the beginning of the human language. This asymmetry seems to be related with a left temporal lobe specialization for intra-specific communication system. Spocter et al. [48] affirm that leftward asymmetry of Wernicke's area originated prior to the appearance of modern human language and before our divergence from the last common ancestor.

Nonetheless, differences between humans and nonhuman primates can be related with the temporal lobe volume. Rilling et al. [49] analyzed the volume of the temporal lobe in different primates. Whole brain, T1-weighted MRI scans were collected from 44 living anthropoid primates spanning 11 species. The surface areas of both the entire temporal lobe and the superior temporal gyrus were measured, as was temporal cortical gyrification. Allometric regressions of temporal lobe structures on brain volume consistently showed apes and monkeys to scale along different trajectories, with the monkeys typically lying at a higher elevation than the apes. Within the temporal lobe, overall volume, surface area, and white matter volume were significantly larger in humans than predicted by the ape regression lines. The largest departure from allometry in humans was for the temporal lobe white matter volume which, in addition to being significantly larger than predicted for brain size, was also significantly larger than predicted for temporal lobe volume. Among the nonhuman primate sample, Cebus have small temporal lobes for their brain size, and Macaca and Papio have large superior temporal gyri for their brain size. The observed departures from allometry might reflect neurobiological adaptations supporting species-specific communication in both humans and Old World monkeys. The authors concluded that entire human temporal lobe and some of its component structures are significantly larger than predicted for a primate brain of human size. The most dramatic allometric departure is in the volume of the human temporal lobe white matter, which, in addition to being large relative to brain size, is also large relative to temporal lobe size. These allometric departures in humans could reflect a reorganization of the temporal lobes driven by expansion of language cortex and its associated connections. It is interesting to note that in primates the superior temporal gyrus contains neurons tuned to species-specific calls, the magnitude of different species' relate to the repertoire of vocal communicative signals as reflections of the complexity of their respective social environments.

It has been calculated that this enlargement of the temporal lobe may have occurred some 200 - 300 thousand years ago [50]. It can thus be conjectured that hominids existing before the contemporary Homo sapiens sapiens could have developed certain complex lexical/semantic communication systems. For instance, it could be speculated that Neanderthal man (Homo sapiens neanderthalensis) could have had a relatively complex language at least as a lexical/semantic system.

\subsection{The Emergence of Grammar}

What was the crucial leap for the development of language grammar? (i.e., syntagmatic dimension of the language). Obviously grammar was initially simple, and "sentences" contained only two words. How to link two words to create a new higher-level unit (syntagm)? Further, how to mark the relationship between the two words? The mechanism has to be the simplest one, and it is not unlikely that it may be similar to the mechanism observed in children during language development.

Suppose that we have two lexical units: animal - fruit.

Different relations between these two words can exist; but the relationship requires an action (verb); it means that there is an interaction between both elements, such as: animal eats fruit; animal has fruit, animal receives fruit; animal likes fruit, etc.

In consequence, before creating a syntagmatic relationship between the words, different word categories have to be separated (e.g., objects and actions).

For creating a phrase, indeed only two types of elements are really required: nouns (nominal phrase) and verbs (verbal phrase). If putting together two words corresponding to two different classes (e.g., animal sleep), there is already a syntagm and grammar has appeared. In childhood language it is observed that words corresponding to two different classes are combined such as, "big dog," “food good," “dad gone.” They contain a grammar, because the words belong to two different classes. In the first two examples ("big dog," "food good,"), there is an existence verb (to be) that is implicit and omitted (as currently observed in some contemporary languages, such as Russian). "Mom dad" is not a phrase, but "mom big" is a primitive sentence.

Brown [51] found that the majority of the utterances at the beginning of the child's grammar could be described by a small set of functional relationships between words:

1) "agent + action" baby kiss

2) “action + object” pull car

3) "agent + object" daddy ball

4) "action + location" sit chair

5) “object + location” cup table

6) “possessor + possession” mommy sock

7) “object + attribute” car red

8) “demonstrative + object” there car

The crucial point in emerging grammar is not the extension of the vocabulary. What is really crucial is to have words corresponding to two different classes that 
can be combined to form a higher-level unit (syntagm). One of the words has to be a noun; the other is a verb. Hence, the problem becomes: how verbs appeared. To create nouns does not seem so complicated (e.g., nouns can be created departing from onomatopoeias, etc. [39]). Verbs, on the other hand, can be created departing from the nouns, but with the meaning of an action (e.g., baby kiss). Action usually means moving, doing, executing, not simply perceiving and associating with some visual (or auditory or tactile) information. "Kiss" can be associated with some sensory information, and obviously the temporal, parietal, and occipital brain areas have to participate ("kiss” as a noun). "Kiss" can also be associated with an action, and obviously the frontal areas have to be involved in this second type of association ("kiss" as a verb). It is well known that impairments in finding nouns are associated with temporal lobe pathology, whereas impairments in finding verbs are associated with left frontal damage and Broca's aphasia [52,53].

Grammatical words, such as prepositions, have an original spatial meaning. Prepositions link words (nouns, pronouns and phrases) in a sentence. A preposition usually indicates the temporal, spatial or logical relationship of its object to the rest of the sentence (e.g., the pencil is on the table; I go to class; etc.). That is, a preposition locates the noun in space (or in time). Simply speaking, the use of preposition as a basic grammatical element supposes a representation of actions (moving, doing, executing).

\subsection{Understanding Broca's Area}

In the last decade there has been a significant interest in re-analyzing the function of Broca's area (e.g., [54-56]). So-called Broca's area includes the pars opercularis (Brodmann's area-BA44) and probably the pars traingularis (BA45) of the inferior frontal gyrus [57] (see Figure 2). BA45 probably is more "cognitive" than BA44, which seems to be more motor, more phonetic. From the traditional point of view, Broca's area corresponds to BA44, but several contemporary authors also include BA45. In the traditional aphasia literature it was assumed that damage in the Broca's area was responsible for the clinical manifestations observed in Broca's aphasia. Only with the introduction of the CT scan did it become evident that the damage restricted to the Broca's area was not enough to produce the "classical” Broca's aphasia; extension to the insula, lower motor cortex, and subjacent subcortical and periventricular white matter is also required [58]. "Broca's area aphasia” ("minor Broca's aphasia”) is characterized by mildly non-fluent speech, relatively short sentences and mild agrammatism; phonetic deviations and a few phonological paraphasias can be observed [59]; some foreign accent can also be noticed [60]. Interestingly, electrical stimulation of Broca's area enhances implicit learning of an artificial grammar [61].

Simultaneously including both BA44 and BA45 inBroca's area is problematic. BA44 is a premotor dysgranular area, whereas BA45 has a granular layer IV and belongs to the heteromodal prefrontal lobe (granular cortex) [62]. So, from a cytoarchitectonic point of view, BA44 and BA45 are quite different. BA44 is a premotor area whereas BA45 corresponds to the prefrontal cortex. From the aphasia perspective, some authors have referred to different clinical manifestations associated with damage in BA44 (Broca-type aphasia) and BA45 (transcortical motor/dynamic aphasia) (e.g., [22]). Broca's area is, more than likely, involved in different language and language related functions [63]. Some authors have pointed out that indeed Broca's area is a collective term that can be fractionated in different subareas [64]. Hagoort [55,65] refers to the "Broca's complex", including BA44 (premotor), and also BA45 and BA47 (prefrontal cortex). He argues that Broca's complex is not a language-specific area, and it becomes active during some nonlanguage activities, such as mental imagery of grasping movements [66]. Functional defined sub-regions could be distinguished in the Broca's complex: BA47 and BA45 are involved in semantic processing, BA44, BA45 and BA46 participate in syntactic processing, and BA44 is involved in phonological processing $[67,68]$. Hagoort [55] proposes that "the common denominator of the Broca's complex is its role in selection and unification operations by which individual pieces of lexical information are bound together into representational structures spanning multiword utterances” (p. 166). Its core function is, consequently, binding the elements of the language. Thompson-Schill [56] analyzed the different deficits observed in cases of damage in the Broca's area: articulation, syntax, selection, and verbal working memory, suggesting that there may be more than a single function of Broca's area.

The author proposes a framework for describing the deficits observed in different patients. The proposed framework suggests that Broca's area may be involved in selecting information among competing sources. Fadiga, Craighero, and Roy [69] speculates that the original role played by Broca's area relates to generating/extracting action meanings; that is, organising/interpreting the sequence of individual meaningless movements. Ardila and Bernal [70] conjectured that the central role of Broca's area was related to sequencing motor/expressive elements. Novick, Trueswell, and Thompson [71] consider that the role of Broca's area is related with a general cognitive control mechanism for the syntactic processing 


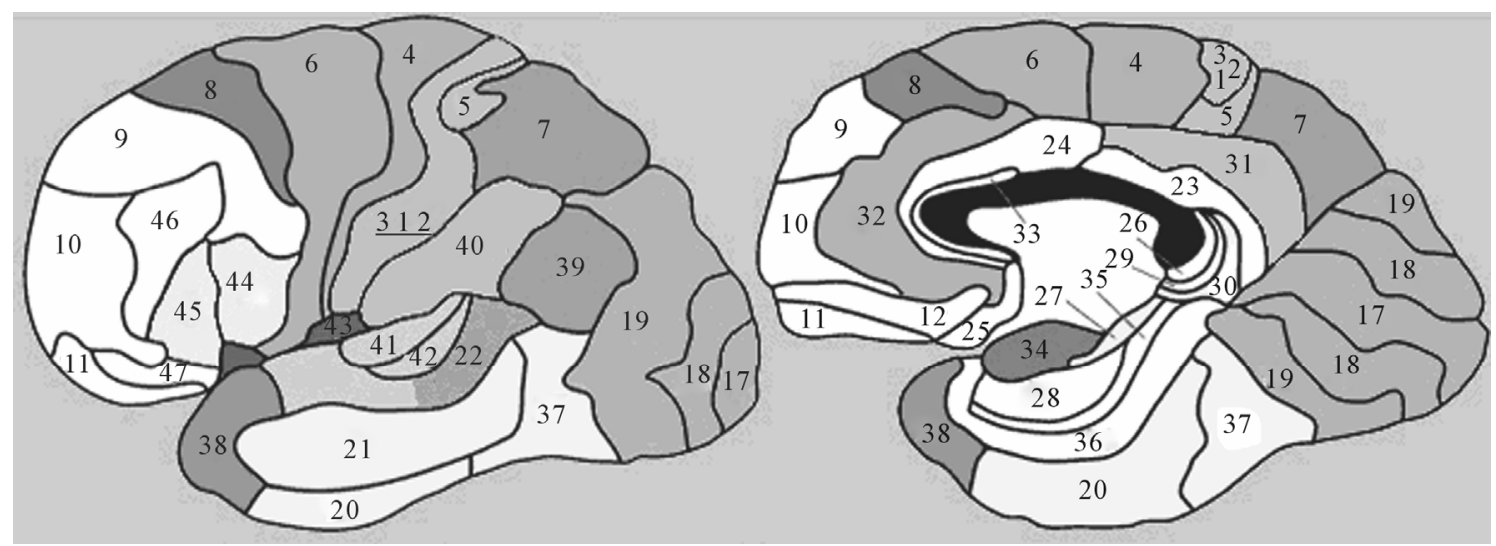

Figure 2. Map illustrating the Brodmann's areas (BA).

of sentences.

Grodzinsky [72-73] has presented an extensive analysis of the role of Broca's area. He proposed that most syntax is not located in Broca's area and its vicinity (operculum, insula, and subjacent white matter). This brain area does have a role in syntactic processing, but a highly specific one: it is the neural home to receptive mechanisms involved in the computation of the relation between transformationally moved phrasal constituents and their extraction sites (syntactic movement). He further assumes that Broca's area is also involved in the construction of higher parts of the syntactic tree in speech production. Interestingly, blood flow in Broca's area increases when participants process complex syntax [74]. Santi and Grodzinsky [75] also recognize its role in working memory related with a specific syntactic role in processing filler-gaps dependency relations. Syntax is indeed neurologically segregated, and its components are housed in several distinct cerebral locations, far beyond the traditional ones (Broca's and Wernicke's regions). A new brain map for syntax would also include portions of the right cerebral hemisphere [76].

Haverkort [77] emphasizes that a clear distinction should be established between linguistic knowledge and linguistic use. Patients with Broca's aphasia have a limitation in the use of grammar, but their grammatical knowledge is available. Broca's aphasia patients present a simplified syntax and phrases are short. They select simpler syntactic structures that are less complex because they impose less burden on working memory. In conesquence, one major factor in Broca's aphasia relates to an impairment in verbal working memory.

In summary, regardless that expressive language disturbances have been associated for over a century with damage in the left inferior frontal gyrus (later known as “Broca's area”), currently there is incomplete agreement about its limits and its specific functions in language. Different proposals have been presented to explain lan- guage disturbances in so-called Broca’s aphasia, as summarized in Table 1.

\subsection{Brain Organization of Nouns and Verbs}

It has been observed that verbs and nouns clearly depend on the activity of different brain areas, and naming objects and actions are disrupted in cases of different types of brain pathology. While speaking or thinking in nouns increased activity is observed in the left temporal lobe, whereas speaking or thinking verbs activates the Broca frontal area [78]. By the same token, impairments in finding nouns are associated with temporal lobe pathology, whereas impairments in finding verbs is associated with left frontal damage and Broca aphasia [52,53]. It has been reported that the damage restricted to the Broca's area can result in a selective defect in finding verbs and name actions whereas objects, colors, body parts, and qualities can be named in a normal way [52]. It has also been observed that naming actions activates the left frontal operculum roughly corresponding to Broca's area [79].

Brain organization of the lexical/semantic system seems to be related to the type of association between words and perceptions (percepts, meanings). When the words are associated with own body information (e.g., the word "finger"), brain representation of the lexicon seems associated with a parietal extension; when the word has visual associations (e.g., the word "book"), an occipital extension is found [80]. That is, the temporal lobe plays the role of discriminating the speech sounds and sequences of sounds (lexicon) but the meaning (semantic) requires an association with one or several sensory modalities.

In anomia it has been traditionally recognized that naming body parts, external objects and colors depend (and are altered) upon the activity of different brain areas [81]. It has also been found that finer distinctions can be 
Table 1. Different proposals about the role of Broca's area.

\begin{tabular}{lc}
\hline \multicolumn{1}{c}{ Function } & Reference \\
\hline Binding the elements of the language & {$[77]$} \\
Selecting information among competing sources & {$[56]$} \\
Generating/extracting action meanings & {$[69]$} \\
Sequencing motor/expressive elements & {$[70]$} \\
Cognitive control mechanism for the syntactic processing of sentences & {$[71]$} \\
Construction of higher parts of the syntactic tree in speech production & {$[72,73]$} \\
Verbal working memory & {$[77]$} \\
\hline
\end{tabular}

made with regard to naming defects, which can be limited to a rather specific semantic category (e.g., people's names, living things, tools, geographical names, etc.) (e.g., [82-85] and even as specific as "medical terms" [86]. A brain "mapping" of the memory organization of different semantic categories could be supposed.

That means that the neural correlates of naming concrete entities such as tools (with nouns) and naming actions (with verbs) are partially distinct: the former are linked to the left inferotemporal region, whereas the latter are linked to the left frontal opercular and left posterior middle temporal regions [87]. Simply speaking, nouns and verbs are related with different brain systems.

\subsection{Two Memory Systems in Language}

Two major memory systems are frequently distinguished in contemporary memory literature: declarative memory (divided into semantic and episodic or experiential) and procedural memory [88]. It has been suggested that the lexical/semantic and grammar aspects of the language are subserved by different neuroanatomic brain circuitries and depend upon these two different memory systems [10-14]. Whereas lexical/semantic aspects of the language depend on a declarative semantic memory (knowledge about the meaning of the words), grammar depends on a procedural memory.

Lexical/semantic aspect of the language is explicitly learned, and represents a type of knowledge we are aware of (declarative memory). It depends on retro-rolandic cortical structures and the hippocampus. Grammar (language sequences, contiguity) is acquired incidentally. Procedural memory for grammar supposes implicit language knowledge. Procedural grammatical learning is related to the execution of sequences of elements (skilled articulatory acts and grammar) used for speaking but also for syntax. Procedural memory is related with frontal/subcortical circuitries [88].

Broca's area damage results in a defect in grammar and also in an inability to find verbs. In consequence, brain representation of actions and brain representation of grammar is coincidental. Using verbs and using grammar depends upon the very same type of brain activity and both are simultaneously disrupted in cases of Broca aphasia. It can be conjectured that verbs and grammar appeared simultaneously in human language; or rather, they are the two sides of the same coin. Furthermore, grammar is associated with oral praxis skills (i.e., agrammatism and apraxia of speech appear simultaneously in Broca aphasia), and hence, all three have to have appeared simultaneously in the evolution of human language: using verbs, using grammar, and rapidly sequencing movements with the articulatory organs. It can be speculated that grammar, speech praxis movements, and using verbs appeared roughly simultaneously in human history. Therefore, they are strongly interrelated and depend upon a common neural activity.

\subsection{There are Only Two Fundamental Aphasia Syndromes}

Since the 19th century it has been well established that there are two major and fundamental aphasic syndromes, named in different ways, but roughly corresponding to Wernicke-type aphasia and Broca-type aphasia (e.g., [19-22,89-99]; see [100] for review). This is a most basic departure point in aphasia: Aphasia is not a single and unified clinical syndrome, but two rather different (even opposed) clinical syndromes. These two major aphasic syndromes have been related with the two basic linguistic operations: selecting (language as paradigm; that is, language as a lexical/semantic system) and sequencing (language as syntagm; that is, language as a grammatical system) [101-103]. Jakobson [104] proposed that aphasia tends to involve one of two types of linguistic deficiency. A patient may lose the ability to use language in two rather different ways: the language impairment can be situated on the paradigmatic axis (similarity disorder due to an impairment in the lexical/semantic knowledge) or the syntagmatic axis (contiguity disorder due to an impairment in the grammatical system).

Luria [103] emphasized that the selection disorder can 
be observed at different levels of the language, corresponding to different aphasia subtypes: phoneme selection (acoustic agnosic aphasia), word selection (acoustic amnesic aphasia), and meaning selection (amnesic aphasia). By the same token, the contiguity disorder can be observed at different levels: sequencing words (kinetic motor aphasia - Broca aphasia) or sequencing sentences (dynamic aphasia - transcorticalmotor aphasia). Noteworthy, different subtypes of Wernicke aphasia are frequently distinguished (e.g., [105]) and Luria's acoustic agnosic, acoustic amnesic, and amnesic aphasia can be considered as subtypes of the language impairment syndrome referred as a whole as Wernicke aphasia.

\subsubsection{Wernicke Aphasia: Grammar without Content}

The Wernicke-type of aphasia represents the clinical syndrome characterized by impairments in the lexical/semantic system. In Wernicke aphasia, the lexical repertoire tends to decrease and language understanding difficulties are evident. Wernicke aphasia patients do not fully discriminate the acoustic information contained in speech. Lexical (word) forms and semantic (meaning) associations become deficient. Patients have problems in recalling the words (memory of the words) and also in associating the words with specific meanings. It means, at least three different deficits underlie Wernicke-type aphasia: (1) phoneme discrimination defects, (2) verbal memory defects, and finally (3) lexical/semantic association deficits [15,106].

In the Wernicke-type of aphasia obviously the language defect is situated at the level of the meaningful words (nouns). Phoneme and word selection are deficient, but language syntax (contiguity: sequencing elements) is well preserved and even overused (paragrammatism in Wernicke aphasia). Nouns seem to depend on an organized pattern of brain activity. Contemporary clinical and neuroimaging studies have corroborated that different semantic categories are differentially impaired in cases of brain pathology (e.g., [80]).

\subsubsection{Broca Aphasia: Content without Grammar}

The Broca-type of aphasia represents the clinical syndrome characterized by impairments in the sequencing process (grammar). It is usually recognized that Broca aphasia has two different distinguishing characteristics: (a) a motor component (lack of fluency, disintegration of the speech kinetic melodies, verbal-articulatory defects, etc. that is usually referred to as apraxia of speech); and (b) agrammatism (e.g., [19,20,22,107]). If both defects are simultaneously observed (i.e., they are very highly correlated), it simply means they both are just two different manifestations of a single underlying defect. It is not easy to understand what could be the single factor responsible for these two clinical manifestations; but it may be kind of an "inability to sequence expressive elements” $[15,70]$. A single common factor underlying both defects should be assumed. Broca's area, most likely, is not specialized in producing language, but in certain neural activities that can support not only skilled movements required for speech, but also morphosyntax. It is interesting to note that deaf-mute subjects (who, in conesquence have never produced verbal articulatory movements) present a virtually total impossibility to learn, understand, and use language grammar [108]. Probably, the lack of normal verbal articulatory development and practice may contribute to this lack of normal grammatical development.

\subsection{Grammar at the Origin of the Executive Functions}

So-called executive functions represent one of the most intensively studied neuroscience questions during the last decade (e.g., [109-113]). Disagreement persists, however, around the potential unitary factor in executive functions [114,115]. Ardila [7] emphasized that "action representtation” (i.e., internally representing movements or actions) may constitute at least one basic executive function factor. It could be speculated that "action representtation” and also "time perception” (potentially derived from action representation) may depend upon one single core ability (“sequencing?”).

Two departing observations are important to support the involvement of prefrontal cortex in motor representation:

1) Anatomical observation. Prefrontal cortex represents an extension and further evolution of the frontal motor areas $[116,117]$. It may be conjectured that the prefrontal lobe should participate in complex and elaborated motor ("executive”) activities.

2) Clinical observation. A diversity of motor control disturbances are observed in prefrontal pathology, such as perseveration, utilization behavior, paratonia, primitive reflexes, etc. (e.g., [118,119]).

Throughout recent history several authors have argued that thought, reasoning, and other forms of complex cognition ("metacognition") depend on an internalization of actions. Vygotsky [120-122] for instance, proposed that thought (and in general, complex cognitive processes) is associated with some "inner speech". Vygotsky represents the most classical author suggesting this interpretation for complex cognition. More recently, Lieberman $[123,124]$ suggested that language in particular and cognition in general arise from complex sequences of motor activities.

The central point in Vygotsky's [121] idea is that 
higher forms of cognition ("cognitive executive functions") depend on certain mediation (language, writing or any other); the instruments used for mediating these complex cognitive processes are culturally developed. According to Vygotsky [121], the invention (or discovery) of these instruments, will result in a new type of evolution (cultural evolution), not requiring any further biological changes. Thinking is interpreted as a covert motor activity ("inner speech"). Vocalization becomes unnecessary because the child "thinks" the words instead of pronouncing them. Inner speech is for oneself, while external, social speech is for others. In brief, Vygotsky [122] argued that complex psychological processes (metacognitive executive functions) derives from language internalization. Thinking relies in the development of an instrument (language or any other), that represents a cultural product.

Lieberman $[123,124]$ refers specifically to the origins of language. He postulates that neural circuits linking activity in anatomically segregated populations of neurons in subcortical structures and the neocortex throughout the human brain regulate complex behaviors such as walking, talking, and comprehending the meaning of sentences. The neural substrate that regulates motor control (basal ganglia, cerebellum, and frontal cortex) in the common ancestor of apes and humans most likely was modified to enhance cognitive and linguistic ability. The cerebellum and prefrontal cortex are also involved in learning motor acts (e.g., [123-126]. Lieberman [123,124] proposes that the frontal regions of the cortex are implicated in virtually all cognitive acts and the acquisition of cognitive criteria; posterior cortical regions are clearly active elements of the brain's dictionary. Real-word knowledge appears to reflect stored conceptual knowledge in regions of the brain traditionally associated with visual perception and motor control. Some aspects of human linguistic ability, such as the basic conceptual structure of words and simple syntax, are phylogenetically primitive and most likely were present in the earliest hominids. Lieberman [123,124] further suggests that speech production, complex syntax, and a large vocabulary developed in the course of hominid evolution, and Homo erectus most likely talked, had large vocabularies, and commanded fairly complex syntax.

These two authors (Vygotsky and Lieberman), although using rather different approaches, have both postulated that the development of language and complex cognition are related with some motor programs, sequencing, internalizing actions, and the like. Many other authors have presented a similar point of view (e.g., [127-132]). Some contemporary research seems to support this interpretation; for instance, Clerget, Winderickx, Fadiga, and Olivier [133] using transcranial magnetic stimulation to interfere transiently with the function of left BA44 in healthy individuals found that a virtual lesion of left BA44 impairs individual performance only for biological actions, and more specifically for object-oriented syntactic actions. The authors concluded that these finding provides evidence that Broca's area plays a crucial role in encoding complex human movements, a process which may be crucial for understanding and/or programming actions.

The recent discovery of mirror neurons [134-136] could significantly contribute to the understanding of the brain organization for verbs. A mirror neuron is a neuron which fires both when an animal performs an action and also when the animal observes the same action performed by another animal. Mirror neurons were initially observed in monkeys [134], but in humans, brain activity consistent with mirror neurons has been found in the premotor cortex and the inferior parietal cortex $[136,137]$. These neurons (mirror neurons) appear to represent a system that matches observed events to similar, internally generated actions.

Transcranial magnetic stimulation and positron emission tomography (PET) experiments suggest that a mirror system for gesture recognition indeed exists in humans and includes Broca's area [135]. The discovery of mirror neurons in Broca's area might have important consequences for understanding brain language organization and language evolution [138,139]. An obvious implication of mirror neurons is that they can participate in the internal representation of actions, and the internal representation of actions may represent the origin of grammar. Neuroimaging data have shown that interacttions involving Broca's area and other cortical areas are weakest when listening to spoken language accompanied by meaningful speech-associated gestures (hence, reducing semantic ambiguity), and strongest when spoken language is accompanied by self grooming hand movements or by no hand movements at all suggesting that Broca's area may be involved in action recognition [140]. PET studies have associated the neural correlates of inner speech with activity of Broca's area [141]. De Zubicaray et al. [142] emphasize the importance of Broca's area to covert verbalization. Clerget et al. [133] using transcranial magnetic stimulation to interfere transiently with the function of left BA44 in healthy individuals found that a virtual lesion of left BA44 impairs individual performance only for biological actions, and more specifically for object-oriented syntactic actions. The authors concluded that these finding provides evidence that Broca's area plays a crucial role in encoding complex human movements, a process which may be crucial for understanding and/or programming actions.

In brief, there is some converging evidence that some- 
thing like "action representation" may constitute the departing point for both, grammar and executive functions.

\section{Conclusions}

Regardless that the distinction between language as a lexical/semantic system and language as a grammatical system is evident in linguistics, this distinction has not been incorporated in contemporary cognitive neurosciences yet, probably due to the frequent assumption that there are several aphasia subtypes and hence, several language functions supported by diverse brain language subsystems. This assumption overlooks the most important and basic departing point in aphasia: in cases of brain pathology language can be disturbed in two rather different ways: as a lexical/semantic system (Wernicke-type aphasia) and as a grammatical system (Broca-type aphasia).

Both language systems not only depend upon different brain areas (temporal and frontal) but also are based on different types of learning (declarative and procedural) supported by different neuroanatomical circuitries. Grammar may be correlated with the ability to represent actions. This is an ability that depends on the so-called Broca's area and related brain circuits, but also depends, is correlated, and likely appeared simultaneously in human history with the ability to rapidly sequence articulatory movements (speech praxis).

Language as a lexical/semantic system may have appeared long before language as a syntactic system, whereas language as a grammatical system may have appeared relatively recently [16,28,29,143-145] and seems to be exclusive to Homo sapiens. Probably, language grammar represents the departing ability for the development of the executive functions and is based in the ability to internally represent actions.

\section{References}

[1] M. H. Christiansen and S. Kirby, "Language Evolution: The States of the Art," Oxford University Press, New York, 2003. doi:10.1093/acprof:oso/9780199244843.001.0001

[2] E. Hoff, “Language Development,” 3rd Edition, Wadsworth, New York, 2003.

[3] J. Oates and A. Grayson, "Cognitive and Language Development in Children,” Blackwell Publishing, Oxford, 2004.

[4] T. Paus, A. Zijdenbos, K. Worsley, D. L. Collins, J. Blumenthal, J. N. Giedd, J. L. Rapoport and A. C. Evans, "Structural Maturation of Neural Pathways in Children and Adolescents: In Vivo Study,” Science, Vol. 283, No. 5409, 1999, pp. 1908-1911. doi:10.1126/science.283.5409.1908

[5] R. Merritt, “Origin of Language,” John Wiley \& Sons, New York, 1994.
[6] W. Enard, M. Przeworski, S. E. Fisher, C. S. Lai, V. Wiebe, T. Kitano, A. P. Monaco and S. Paabo, "Molecular Evolution of FOXP2, a Gene Involved in Speech and Language," Nature, Vol. 418, No. 6900, 2002, pp. 869-872. doi:10.1038/nature01025

[7] A. Ardila, "On the Evolutionary Origins of Executive Functions,” Brain and Cognition, Vol. 68, No. 1, 2008, pp. 92-99. doi:10.1016/j.bandc.2008.03.003

[8] J. R. Binder, J. A. Frost, T. A. Hammeke, R. W. Cox, S. M. Rao and T. Prieto, "Human Brain Language Areas Identified by Functional Magnetic Resonance Imaging," The Journal of Neurosciences, Vol. 17, No. 1, 1997, pp. 353-362.

[9] B. Bernal and J. Perdomo, “Brodmann's Interactive Atlas 1.1.” http://www.fmriconsulting.com/brodmann/

[10] F. Fabbro, "The Bilingual Brain, Cerebral Representation of Languages,” Brain and Language, Vol. 79, No. 2, 2001, pp. 211-222. doi:10.1006/brln.2001.2481

[11] F. Fabbro, "The Neurolinguistics of Bilingualism: An Introduction,” Psychology Press, East Sussex, 1999.

[12] M. Paradis, "A Neurolinguistic Theory of Bilingualism," John Benjamins, Amsterdam, 2004.

[13] M. T. Ullman, "The Declarative/Procedural Model of Lexicon and Grammar," Journal of Psycholinguistic Research, Vol. 30, No. 1, 2001, pp. 37-69. doi:10.1023/A:1005204207369

[14] M. T. Ullman, "Contributions of Memory Circuits to Language: The Declarative/Procedural Model,” Cognition, Vol. 92, No. 1-2, 2004, pp. 231-270. doi:10.1016/j.cognition.2003.10.008

[15] A. Ardila, "A Proposed Reinterpretation and Reclassification of Aphasic Syndromes,” Aphasiology, Vol. 24, No. 3, 2010, pp. 363-394. doi:10.1080/02687030802553704

[16] R. Jakobson, "Child Language, Aphasia, and Phonological Universals,” Mouton Press, Hague, 1968.

[17] N. Chomsky, "Aspects of the Theory of Syntax," MIT Press, Cambridge, 1965.

[18] D. F. Benson, “Aphasia, Alexia and Agraphia,” Churchill Livingstone, New York, 1979.

[19] D. F. Benson and A. Ardila, "Aphasia: A Clinical Perspective,” Oxford University Press, New York, 1996.

[20] A. Kertesz, “Aphasia and Associated Disorders,” Grune and Stratton, New York, 1979.

[21] K. Goldstein, "Language and Language Disturbances," Grune and Stratton, New York, 1948.

[22] A. R. Luria, "Basic Problems of Neurolinguistics," Mouton Press, Hague, 1976.

[23] C. Wernicke, "Der Aphasiche Symptomencomplex," Cohn and Weigert, 1874.

[24] D. Bickerton, “Adam's Tongue,” Hill and Wang, New York, 2009.

[25] M. A. Nowak and N. L. Komarova, "Towards an Evolutionary Theory of Language," Trends in Cognitive Sciences, Vol. 5, No. 7, 2001, pp. 288-295. doi:10.1016/S1364-6613(00)01683-1 
[26] A. Ardila, "Origins of the Language: Correlation between Brain Evolution and Language Development,” In: S. M. Platek and T. K. Shackelford, Eds., Foundations of Evolutionary Cognitive Neuroscience, Cambridge University Press, New York, 2009, pp. 153-174. doi:10.1017/CBO9780511626586.006

[27] F. X. Plooij, "Some Basic Traits of Language in Wild Chimpanzees?” In: A. Lock, Ed., Action, Gesture and Symbol, Academic Press, New York, 1978, pp. 121-144.

[28] F. Vargha-Khadem, K. E. Watkins, C. J. Price, J. Ashburner, K. J. Alcock, A. Connelly, R. S. Frackowiak, K. J. Friston, M. E. Pembrey, M. Mishkin, D. G. Gadian and R. E. Passingham, "Neural Basis of an Inherited Speech and Language Disorder," Proceedings of the National Academy of Sciences, Vol. 95, No. 21, 1998, pp. 12695-12700. doi:10.1073/pnas.95.21.12695

[29] S. C. Vernes, J. Nicod, F. M. Elahi, J. A. Coventry, N. Kenny, A. M. Coupe, L. E. Bird, K. E. Davies and S. E. Fisher, "Functional Genetic Analysis of Mutations Implicated in a Human Speech and Language Disorder," Human Molecular Genetics, Vol. 15, No. 21, 2006, pp. 3154-3167. doi:10.1093/hmg/ddl392

[30] D. Bickerton, “Language and Species,” The University of Chicago Press, Chicago, 1990.

[31] J. McCrone, "The Ape that Spoke: Language and the Evolution of the Human Mind,” Avon Books, New York, 1991.

[32] D. L. Cheney and R. M. Seyfarth, "Why Animals don't have Language," The Tanner Lectures on Human Values, Vol. 19, 1997, pp. 173-210.

[33] K. J. Hayes and C. Hayes, "Imitation in a Home-Raised Chimpanzee,” Journal of Comparative and Physiological Psychology, Vol. 45, No. 5, 1952, pp. 450-459. doi:10.1037/h0053609

[34] R. A. Gardner and B. T. Gardner, "Teaching Sign Language to a Chimpanzee," Science, Vol. 165, No. 3894, 1969, pp. 664-672. doi:10.1126/science.165.3894.664

[35] J. Limber, "What can Chimps Tell Us about the Origins of Language?” In: S. Kuczaj, Ed., Language Development, Hillsdale, Vol. 2, 1982, pp. 429-446.

[36] F. Patterson and E. Linden, "The Education of Koko," Holt, Rinehart and Winston, New York, 1981.

[37] J. Mitani, "Review of Savage-Rumbaugh and Lewin's 'Kanzi: The Ape at the Brink of the Human Mind',' Scientific American, Vol. 272, 1995, pp. 43-54.

[38] S. Savage-Rumbaugh and R. Lewin, "Kanzi: The Ape at the Brink of the Human Mind,” John Wiley \& Sons, New York, 1974.

[39] G. Yule, “The Study of Language,” Cambridge University Press, Cambridge, 1996.

[40] J. K. Rilling, M. F. Glasse, T. M. Preuss, X. Ma, T. Zhao, $\mathrm{X}$. Hu and T. E. Behrens, "The Evolution of the Arcuate Fasciculus Revealed with Comparative DTI," Nature Neurosciences, Vol. 11, No. 4, 2008, pp. 426-428. doi:10.1038/nn2072

[41] J. P. Rauschecker, B. Tian and M. Hauser, "Processing of Complex Sounds in the Macaque Nonprimary Auditory
Cortex,” Science, Vol. 268, No. 5207, 1995, pp. 111-114. doi:10.1126/science.7701330

[42] J. P. Taglialatela, J. L. Russell, J. A. Schaeffer and W. D. Hopkins, "Visualizing Vocal Perception in the Chimpanzee Brain,” Cerebral Cortex, Vol. 19, No. 5, 2009, pp. 1151-1157. doi:10.1093/cercor/bhn157

[43] X. Wang, M. M. Merzenich, R. Beitel and C. E. Schreiner, "Representation of a Species-Specific Vocalization in the Primary Auditory Cortex of the Common Marmoset: Temporal and Spectral Characteristics,” Journal of Neurophysiology, Vol. 74, No. 6, 1995, pp. 2685-2706.

[44] Z. Wollberg and J. D. Newman, “Auditory Cortex of Squirrel Monkey: Response Patterns of Single Cells to Species-Specific Vocalizations,” Science, Vol. 175, No. 4108, 1972, pp. 212-214. doi:10.1126/science.175.4018.212

[45] P. J. Gannon, R. L. Holloway, D. C. Broadfield and A. R. Braun, "Asymmetry of Chimpanzee Planum Temporale: Humanlike Pattern of Wernicke's Brain Language Area Homolog,” Science, Vol. 279, No. 5348, 1998, pp. 220222. doi:10.1126/science.279.5348.220

[46] P. L. Heilbroner and R. L. Holloway, "Anatomical Brain Asymmetries in New World and Old World Monkeys: Stages of Temporal Lobe Development in Primate Evolution," American Journal of Physical Anthropology, Vol. 76, No. 1, 1988, pp. 39-48. doi:10.1002/ajpa.1330760105

[47] W. D. Hopkins and T. M. Nir, "Planum Temporale Surface Area and Grey Matter Asymmetries in Chimpanzees (Pan Troglodytes): The Effect of Handedness and Comparison with Findings in Humans," Behavioral and Brain Research, Vol. 208, No. 2, 2010, pp. 436-443. doi:10.1016/j.bbr.2009.12.012

[48] M. A. Spocter, W. D. Hopkins, A. R. Garrison, A. L. Bauernfeind, C. D. Stimpson, P. R. Hof and C. C. Sherwood, "Wernicke's Area Homologue in Chimpanzees (Pan Troglodytes) and Its Relation to the Appearance of Modern Human Language,” Proceedings Biological Sciences, Vol. 277, No. 1691, 2010, pp. 2165-2174. doi:10.1098/rspb.2010.0011

[49] J. K. Rilling and R. A. Seligman, “A Quantitative Morphometric Comparative Analysis of the Primate Temporal Lobe,” Journal of Human Evolution, Vol. 42, No. 5, 2002, pp. 505-533. doi:10.1006/jhev.2001.0537

[50] V. I. Kochetkova, "Paleoneurology,” Moscow State University Press, Moscow, 1973.

[51] R. Brown, “A First Language: The Early Stages,” Harvard University Press, Cambridge, 1973.

[52] A. Ardila and M. Rosselli, "Averbia as a Selective Naming Disorder: A Single Case Report,” Journal of Psycholinguist Research, Vol. 23, 1994, pp. 139-148. doi:10.1007/BF02143920

[53] A. R. Damasio and D. Tranel, "Nouns and Verbs are Retrieved with Differently Distributed Neural Systems," Proceedings of the National Academy of Sciences, Vol. 90, No. 11, 1993, pp. 4957-4960. doi:10.1073/pnas.90.11.4957

[54] Y. Grodzinsky and K. Amunts, "Broca’s Region,” Oxford University Press, New York, 2006. 
doi:10.1093/acprof:oso/9780195177640.001.0001

[55] P. Hagoort, "Broca's Complex as the Unification Space for Language,” In: A. Cutler, Ed., Twenty-first Century Psycholinguistics: Four Cornerstones, Lawrence Erlbaum Associates Inc., New Jersey, 2005, pp. 157-172.

[56] S. Thompson-Schill, "Dissecting the Language Organ: A New Look at the Role of Broca's Area in Language Processing,” In: A. Cutler, Ed., Twenty-first Century Psycholinguistics: Four Cornerstones, Lawrence Erlbaum Associates Inc., New Jersey, 2005, pp. 173-189.

[57] A. Foundas, K. Eure, L. Luevano and D. Weinberger, "MRI Asymmetries of Broca's Area: The Pars Triangularis and Pars Opercularis,” Brain and Language, Vol. 64, No. 3, 1998, pp. 282-296. doi:10.1006/brln.1998.1974

[58] M. P. Alexander, M. A. Naeser and C. Palumbo, “Broca’s Area Aphasias: Aphasia after Lesions Including the Frontal Operculum,” Neurology, Vol. 40, No. 2, 1990, pp. 353-362.

[59] J. P. Mohr, M. S. Pessin, S. Finkelstein, H. H. Funkenstein, G. W. Duncan and K. R. Davis, "Broca Aphasia: Pathologic and Clinical,” Neurology, Vol. 28, 1978, pp. 311-324.

[60] A. Ardila, M. Rosselli and O. Ardila, "Foreign Accent: An Aphasic Epiphenomenon?” Aphasiology, Vol. 2, No. 5, 1988, pp. 493-499. doi:10.1080/02687038808248955

[61] M. H. de Vries, A. C. Barth, S. Maiworm, S. Knecht, P. Zwitserlood and A. Flöel, "Electrical Stimulation of Broca's Area Enhances Implicit Learning of an Artificial Grammar,” Journal of Cognitive Neuroscience, Vol. 22, No. 11, 2010, pp. 2427-2436. doi:10.1162/jocn.2009.21385

[62] M. M. Mesulam, “The Human Frontal Lobes: Transcending the Default Mode through Contingent Encoding,” In: D. T. Stuss and R. T. Knight, Eds., Principles of Frontal Lobe Function, Oxford University Press, Oxford, 2002, pp. 8-31. doi:10.1093/acprof:oso/9780195134971.003.0002

[63] G. R. Fink, Z. M. Manjaly, K. E. Stephan, J. M. Gurd, K. Zilles and K. Amunts, “A Role for Broca's Area beyond Language Processing: Evidence from Neuropsychology and fMRI,” In: Y. Grodzinky and K. Amunts, Eds., Broca's Region, Oxford University Press, Oxford, 2006, pp. 254-268. doi:10.1093/acprof:oso/9780195177640.003.0016

[64] R. Lindenberg, H. Fangerau and R. J. Seitz, “'Broca’s Area' as a Collective Term?” Brain and Language, Vol. 102, No. 1, 2007, pp. 22-29. doi:10.1016/j.bandl.2006.11.012

[65] P. Hagoort, "On Broca, Brain, and Binding," In: Y. Grodzinky and K. Amunts, Eds., Broca's Region, Oxford University Press, Oxford, 2006, pp. 242-253. doi:10.1093/acprof:oso/9780195177640.003.0015

[66] J. Decety, D. Perani, M. Jeannerod, V. Bettinard, B. Tadardy and R. Woods, "Mapping Motor Representations with Positron Emission Tomography,” Nature, Vol. 371, No. 6498, 2004, pp. 600-602. doi:10.1038/371600a0

[67] S. Heim, S. B. Eickhoff and K. Amunts, "Specialisation in Broca's Region for Semantic, Phonological, and Syntactic Fluency?” Neuroimage, Vol. 40, No. 3, 2008, pp.
1362-1368. doi:10.1016/j.neuroimage.2008.01.009

[68] N. T. Sahin, S. Pinker, S. S. Cash, D. Schomer and E. Halgren, "Sequential Processing of Lexical, Grammatical, and Phonological Information within Broca's Area," Science, Vol. 326, No. 5951, 2009, pp. 445-449. doi:10.1126/science.1174481

[69] L. Fadiga, L. Craighero and A. Roy, "Broca’s Region: A Speech Area?” In: Y. Grodzinky and K. Amunts, Eds., Broca's Region, Oxford University Press, Oxford, 2006, pp. 137-152. doi:10.1093/acprof:oso/9780195177640.003.0009

[70] A. Ardila and B. Bernal, "What can be Localized in the Brain? Towards a "Factor" Theory on Brain Organization of Cognition,” International Journal of Neurosciences, Vol. 117, No. 7, pp. 2007, 935-969. doi:10.1080/00207450600912222

[71] J. M. Novick, J. C. Trueswell and S. L. Thompson, "Cognitive Control and Parsing: Reexamining the Role of Broca's Area in Sentence Comprehension,” Cognitive, Affective \& Behavioral Neuroscience, Vol. 5, No. 3, 2005, pp. 263-281. doi:10.3758/CABN.5.3.263

[72] Y. Grodzinsky, “The Neurology of Syntax: Language Use without Broca's Area,” Behavioral and Brain Sciences, Vol. 23, No. 1, 2000, pp. 1-21. doi:10.1017/S0140525X00002399

[73] Y. Grodzinsky, “The Language Faculty, Broca’s Region, and the Mirror System,” Cortex, Vol. 42, No. 4, 2006, pp. 464-468. doi:10.1016/S0010-9452(08)70378-2

[74] D. Caplan, A. Alpert, G. Waters and A. Olivieri, "Activation of Broca's Area by Syntactic Processing under Conditions of Concurrent Articulation," Human Brain Mapping, Vol. 9, No. 2, 2000, pp. 65-71. doi:10.1002/(SICI)1097-0193(200002)9:2<65::AID-HB M1>3.0.CO;2-4

[75] A. Santi and Y. Grodzinsky, "Working Memory and Syntax Interact in Broca's Area,” Neuroimage, Vol. 37, No. 1, 2007, pp. 8-17. doi:10.1016/j.neuroimage.2007.04.047

[76] Y. Grodzinsky and A. D. Friederici, "Neuroimaging of Syntax and Syntactic Processing," Current Opinions in Neurobiology, Vol. 16, No. 2, 2006, pp. 240-246. doi:10.1016/j.conb.2006.03.007

[77] M. Haverkort, "Linguistic Representation and Language Use in Aphasia,” In: A. Cutler, Ed., Twenty-First Century Psycholinguistics: Four Cornerstones, Lawrence Erlbaum Associates Inc., New Jersey, 2005, pp. 57-68.

[78] M. E. Raichle, "Visualizing the Mind," Scientific American, Vol. 270, 1994, pp. 58-65. doi:10.1038/scientificamerican0494-58

[79] H. Damasio, T. J. Grabowski, D. Tranel, L. L. Ponto, R. D. Hichwa and A. R. Damasio, "Neural Correlates of Naming Actions and of Naming Spatial Relations," Neuroimage, Vol. 13, 2001, pp. 1053-1064. doi:10.1006/nimg.2001.0775

[80] F. E. Roux, V. Lubrano, V. Lauwers-Cances, C. R. Mascott and J. F. Demonet, "Category-Specific Cortical Mapping: Color-Naming Areas,” Journal of Neurosurgery, Vol. 104, No. 1, 2006, pp. 27-37. 
doi:10.3171/jns.2006.104.1.27

[81] H. Hecaen and M. L. Albert, "Human Neuropsychology," John Wiley \& Sons, New York, 1978.

[82] D. M. Harris and J. Kay, "Selective Impairment of the Retrieval of People's Names: A Case of Category Specificity,” Cortex, Vol. 31, No. 3, 1995, pp. 575-582.

[83] H. Goodglass, A. Wingfield, M. R. Hyde and J. C. Theurkauf, "Category Specific Dissociations in Naming and Recognition by Aphasic Patients," Cortex, Vol. 22, No. 1, 1986, pp. 87-102.

[84] F. Lyons, J. R. Hanley and J. Kay, “Anomia for Common Names and Geographical Names with Preserved Retrieval of Names of People: A Semantic Memory Disorder," Cortex, Vol. 38, 2002, pp. 23-35. doi:10.1016/S0010-9452(08)70636-1

[85] E. K. Warrington and T. Shallice, "Category Specific Semantic Impairments,” Brain, Vol. 107, 1984, pp. 829-854. doi:10.1093/brain/107.3.829

[86] B. Crosson, P. J. Moberg, J. R. Boone, L. J. Rothi and A. Raymer, "Category Specific Naming Deficit for Medical Terms after Dominant Thalamic/Capsular Hemorrhage," Brain and Language, Vol. 60, No. 3, 1997, pp. 407-442. doi:10.1006/brln.1997.1899

[87] D. Tranel, C. Martin, H. Damasio, T. J. Grabowski and R. Hichwa, "Effects of Noun-Verb Homonymy on the Neural Correlates of Naming Concrete Entities and Actions,” Brain and Language, Vol. 92, 2005, pp. 288-299. doi:10.1016/j.bandl.2004.01.011

[88] E. Tulving, I. Fergus and M. Craik, "The Oxford Handbook of Memory,” Oxford University Press, Oxford, 2004.

[89] M. L. Albert, H. Goodglass, N. A. Helm, A. B. Rubers and M. P. Alexander, "Clinical Aspects of Dysphasia," Springer-Verlag, New York, 1981.

[90] M. P. Alexander and D. F. Benson, "The Aphasia and Related Disturbances,” In: R. J. Joynt, Ed., Clinical Neurology, Lippincott, Philadelphia, 1991, pp. 1-58.

[91] D. C. Bastian, “Aphasia and Other Speech Defects,” H. K. Lewis, London, 1898.

[92] S. Freud, "Las Afasias,” Ediciones Nueva Visión, Buenos Aires, 1891/1973.

[93] H. Head, "Aphasia and Kindred Disorders of Speech," Cambridge University Press, London, 1926.

[94] H. Hecaen, "Introduction a la Neuropsychologie," Larousse, Paris, 1972.

[95] L. Lichtheim, “On Aphasia,” Brain, Vol. 7, No. 4, 1885, pp. 433-484.

[96] A. Pick, “Aphasia,” Charles C. Thomas, Springfield, 1931.

[97] H. Schuell, J. J. Jenkins and E. Jimenez-Pabon, "Aphasia in Adults,” Harper and Row, New York, 1964.

[98] M. Taylor-Sarno, “Acquired Aphasia,” Academic Press, New York, 1998.

[99] S. A. K. Wilson, “Aphasia,” Kegan Paul, London, 1926.

[100] J. Tesak and C. Code, "Milestones in the History of Aphasia: Theories and Protagonists,” Psychology Press,
New York, 2008.

[101] R. Jakobson, "Studies on Child Language and Aphasia," Mouton, Hague, 1971.

[102] R. Jakobson and M. Halle, “Two Aspects of Language and Two Types of Aphasic Disturbances," Mouton, Hague, 1956.

[103]A. R. Luria, "Sobre las dos Formas Basicas de Alteraciones Afasicas en el Lenguaje,” In: A. Ardila, Ed. Psicobiologia del Lenguaje, Trillas, Mexico, 1972/1983.

[104] R. Jakobson, “Toward a Linguistic Typology of Aphasic Impairments,” In: A. V. S. DeReuck and M. O’Connor, Eds., Disorders of Language, Little and Brown, Boston, 1964, pp. 84-101.

[105] A. Ardila, “Las Aphasias,” 2006. http://www.aphasia.org/ libroespanol.php. Accessed 05/09/2010.

[106] A. Ardila, “Toward a Model of Phoneme Perception,” International Journal of Neuroscience, Vol. 70, No. 1, 1993, pp. 1-12. doi:10.3109/00207459309000556

[107] A. Kertesz, “Aphasia,” In: J. A. M. Frederiks, Ed., Handbook of Clinical Neurology, vol 45: Clinical Neuropsychology, Elsevier, 1985, pp. 287-322.

[108] H. Poizner, E. S. Klima and U. Bellugi, "What the Hands Reveal about the Brain,” MIT Press, Cambridge, 1987.

[109] A. Garcia-Molina, J. Tirapu-Ustarroz, P. Luna-Lario, J. Ibanez and P. Duque, "Son lo Mismo Inteligencia y Funciones Ejecutivas?” Revista de Neurologia, Vol. 50, 2010, pp. 738-746.

[110] E. Koechlin, C. Ody and F. Kouneiher, "The Architecture of Cognitive Control in the Human Prefrontal Cortex," Science, Vol. 302, No. 5648, 2003, pp. 1181-1185. doi:10.1126/science.1088545

[111] E. K. Miller and J. D. Cohen, “An Integrative Theory of Prefrontal Cortex Function,” Annual Review of Neurosciences, Vol. 24, 2001, pp. 167-202. doi:10.1146/annurev.neuro.24.1.167

[112] D. Stuss and R. T. Knight, “The Frontal Lobes,” Oxford University Press, Oxford, 2002. doi:10.1093/acprof:oso/9780195134971.001.0001

[113] D. T. Stuss and L. B. Levine, "Adult Clinical Neuropsychology: Lessons from Studies of the Frontal Lobes," Annual Review of Psychology, Vol. 53, 2002, pp. 401-433. doi:10.1146/annurev.psych.53.100901.135220

[114] A. Miyake, N. P. Friedman, M. J. Emerson, A. H. Witzki, A. Howerter and T. D. Wager, "The Unity and Diversity of Executive Functions and Their Contributions to Complex 'Frontal Lobe' Tasks: A Latent Variable Analysis," Cognitive Psychology, Vol. 41, 2000, pp. 49-100. doi:10.1006/cogp.1999.0734

[115] D. R. Stuss and M. P. Alexander, "Is There a Dysexecutive Syndrome?” Philosophical Transactions of the Royal Society of London. Series B, Biological Sciences, Vol. 362, 2007, pp. 901-915. doi:10.1098/rstb.2007.2096

[116] B. L. Miller and J. L. Cummings, "The Human Frontal Lobes: Functions and Disorders,” Guilford Press, New York, 2007.

[117] J. Risberg, "Evolutionary Aspects of the Frontal Lobes,” 
In: J. Risberg and J. Grafman, Eds., The Frontal Lobes. Development, Function and Pathology, Cambridge University Press, New York, 2006, pp. 1-20. doi:10.1017/CBO9780511545917.003

[118] A. Ardila and M. Rosselli, "Neuropsicologia Clinica,” Manual Moderno, Mexico, 2007.

[119] M. Victor and A. H. Ropper, “Adams \& Victor's Principles of Neurology,” McGraw-Hill, New York, 2001.

[120] L. S. Vygotsky, "The Problem of the Cultural Development of the Child II,” Journal of Genetic Psychology, Vol. 36, No. 3, 1929, pp. 415-432.

[121] L. S. Vygotsky, “Thought and Language,” MIT Press, Cambridge, 1934/1962.

[122] L. S. Vygotsky, “Mind in Society,” Harvard University Press, Cambridge, 1934/1978.

[123] P. Lieberman, "Human Language and Our Reptilian Brain,” Harvard University Press, Cambridge, 2002.

[124] P. Lieberman, "On the Nature and Evolution of the Neural Bases of Human Language," Yearbook of Physical Anthropology, Vol. 45, 2002, pp. 36-62. doi:10.1002/ajpa.10171

[125] M. Matsumura, N. Sadato, T. Kochiyama, S. Nakamura, E. Naito and K. Matsunami, "Role of the Cerebellum in Implicit Motor Skill Learning: A PET Study,” Brain Research Bulletin, Vol. 63, No. 6, 2004, pp. 471-483. doi:10.1016/j.brainresbull.2004.04.008

[126] S. Hernandez-Mueller, F. Mulas and L. Mattos, "La Contribución del Cerebelo a los Procesos Cognitivos,” Revista de Neurología, Vol. 40 (Suppl. 1), 2005, pp. S57-S64.

[127] B. Hommel, J. Müsseler, G. Aschersleben and W. Prinz, "The Theory of Event Coding (TEC): A Framework for Perception and Action Planning," Behavioral and Brain Sciences, Vol. 24, No. 5, 2001, pp. 849-937. doi:10.1017/S0140525X01000103

[128] M. Jeannerod, "The Cognitive Neuroscience of Action," Wiley-Blackwell, Hoboken, 1997.

[129] A. R. Luria, “Frontal Lobe Syndromes,” In: P. J. Vinken and G. W. Bruyn, Eds., Handbook of Clinical Neurology, North Holland, Amsterdam, 1969, pp. 725-757.

[130] E. Morsella, J. A. Bargh and P. M. Gollwitzer, "Oxford Handbook of Human Action,” Oxford University Press, Oxford, 2009.

[131] W. Prinz, "Perception and Action Planning," European Journal of Cognitive Psychology, Vol. 9, No. 2, 1997, pp. 129-154. doi:10.1080/713752551

[132]R. W. Sperry, "Neurology and the Mind-body Problem," American Scientist, Vol. 40, 1952, pp. 291-312.

[133] E. Clerget, A. Winderickx, L. Fadiga and E. Olivier, "Role of Broca's Area in Encoding Sequential Human Actions: A Virtual Lesion Study,” Neuroreport, Vol. 20,
No. 16, 2009, pp. 1496-1499. doi:10.1097/WNR.0b013e3283329be8

[134] G. Di Pellegrino, L. Fadiga, L. Fogassi, V. Gallese and G. Rizzolatti, "Understanding Motor Events: A Neurophysiological Study,” Experimental Brain Research, Vol. 91, 1992, pp. 176-180.

[135] G. Rizzolatti and M. A. Arbib, "Language within Our Grasp,” Trends in Neurosciences, Vol. 21, No. 5, 1998, pp. 188-194. doi:10.1016/S0166-2236(98)01260-0

[136] G. Rizzolatti, L. Fadiga, V. Gallese and L. Fogassi, "Premotor Cortex and the Recognition of Motor Actions,” Cognitive Brain Research, Vol. 3, No. 2, 1996, pp. 131-141. doi:10.1016/0926-6410(95)00038-0

[137] G. Rizzolatti and L. Craighero, "The Mirror-Neuron System,” Annual Review of Neuroscience, Vol. 27, 2004, pp. 169-192. doi:10.1146/annurev.neuro.27.070203.144230

[138] M. A. Arbib, “Aphasia, Apraxia and the Evolution of the Language-Ready Brain,” Aphasiology, Vol. 20, No. 9-11, 2006, pp. 1125-1155. doi:10.1080/02687030600741683

[139] L. Craighero, M. Metta, G. Sandini and L. Fadiga, "The Mirror-Neurons System: Data and Models,” Progress in Brain Research, Vol. 164, 2007, pp. 39-59. doi:10.1016/S0079-6123(07)64003-5

[140] J. I. Skipper, S. Goldin-Meadow, H. C. Nusbaum and S. L. Small, "Speech Associated Gestures, Broca's Area, and the Human Mirror System,” Brain and Language, Vol. 101, No. 3, 2007, pp. 260-277. doi:10.1016/j.bandl.2007.02.008

[141] P. K. McGuire, D. A. Silbersweig, R. M. Murray, A. S. David, R. S. J. Frackowiak and C. D. Frith, "Functional Anatomy of Inner Speech and Auditory Verbal Imagery," Psychological Medicine, Vol. 26, No. 1, 1996, pp. 29-38. doi:10.1017/S0033291700033699

[142] G. de Zubicaray, N. Postle, K. McMahon, M. Meredith and R. Ashton, "Mirror Neurons, the Representation of Word Meaning, and the Foot of the Third Left Frontal Convolution,” Brain and Language, Vol. 112, No. 1, 2010, pp. 77-84. doi:10.1016/j.bandl.2008.09.011

[143] S. E. Fisher and C. Scharff, "FOXP2 as a Molecular Window into Speech and Language,” Trends in Genetics, Vol. 25, No. 4, 2009, pp. 166-177. doi:10.1016/j.tig.2009.03.002

[144] D. F. Newbury, S. E. Fisher and A. P. Monaco, "Recent Advances in the Genetics of Language Impairment,” Genome Medicine, Vol. 2, 2010, p. 6.

[145] H. Takahashi, K. Takahashi and F. C. Liu, "FOXP Genes, Neural Development, Speech and Language Disorders," Advances in Experimental Medicine and Biology, Vol. 665, 2009, pp. 117-129. doi:10.1007/978-1-4419-1599-3_9 